\title{
New investigations of the Epipalaeolithic in western Central Asia: Obishir-5
}

\author{
Svetlana V. Shnaider ${ }^{1,2,3, *}$, Maciej T. Krajcarz ${ }^{4}$, T. Bence Viola ${ }^{1,5}$, \\ Aida Abdykanova ${ }^{6}$, Ksenia A. Kolobova ${ }^{1,2}$, \\ Alexander Yu. Fedorchenko, ${ }^{1,2}$, Saltanat Alisher-kyzy ${ }^{3}$ \\ $\&$ Andrei I. Krivoshapkin ${ }^{1,2,3}$
}

Intensive research on the Mesolithic of western Central Asia began in the mid twentieth century, when the discovery of key sites allowed for the formulation of the main regional cultural-chronological schemes (Figure 1).

The assemblage from Obishir-5, a site located in the southern part of the Fergana Valley (in Batken District, south Kyrgyzstan; Figure 2) played a crucial role in archaeological interpretation. The site was discovered by U.I. Islamov in 1965, and a total area of $141 \mathrm{~m}^{2}$ was excavated over seven field seasons during the 1960s-1970s.

Between four and seven stratigraphic layers were identified in different parts of the site; layer 2 contained remains of the Late Iron Age-early medieval period (first to seventh centuries AD), while the lower layers (3-7) contained Mesolithic assemblages. The Mesolithic lithics and animal bones were analysed as one accumulation and dated to 9000$8000 \mathrm{BC}$. According to Islamov (1980), the lithic industry is dominated by bladelets and microblades with alternate and ventral retouch, isolated segments and choppers.

In 2015, we started large-scale fieldwork as part of interdisciplinary studies of Epipalaeolithic settlements in western Central Asia. Obishir-5 was excavated in the framework of this project in 2015-2016, with further excavations planned in the following years. A total of $8 \mathrm{~m}^{2}$ in the western part of U.I. Islamov's original excavation area (Figure 3) have so far been excavated. Six stratigraphic layers, mostly of colluvial origin, were revealed: layer 0 , modern topsoil; layer 1 , light grey to pale brown thin-laminated silt, containing archaeological material from the Early Middle Ages; layers 2 and 3, light brown to dark brown colluvial loam; layer 4, loess-like cream to yellowish-brown colluvial loams with limestone clasts; layer 5 can be considered as a typical loess that was most probably formed

\footnotetext{
1 Institute of Archaeology and Ethnography of the Siberian Branch of the Russian Academy of Sciences, 17 Academician Lavrentiev Avenue, Novosibirsk 630090, Russia

Altai State University, 61 Lenina Prospect, Barnaul 656049, Russia

Novosibirsk State University, 1 Pirogova Street, Novosibirsk 630090, Russia

Institute of Geological Sciences, Polish Academy of Sciences, 51/55 Twarda Street, Warsaw 00-818, Poland Department of Anthropology, University of Toronto, 19 Russell Street, Toronto, ON M5S 2S2, Canada

American University of Central Asia, 7/6 Aaly Tokombaev Street, Bishkek 720060, Kyrgyz Republic

Author for correspondence (Email: sveta.shnayder@gmail.com)
} 


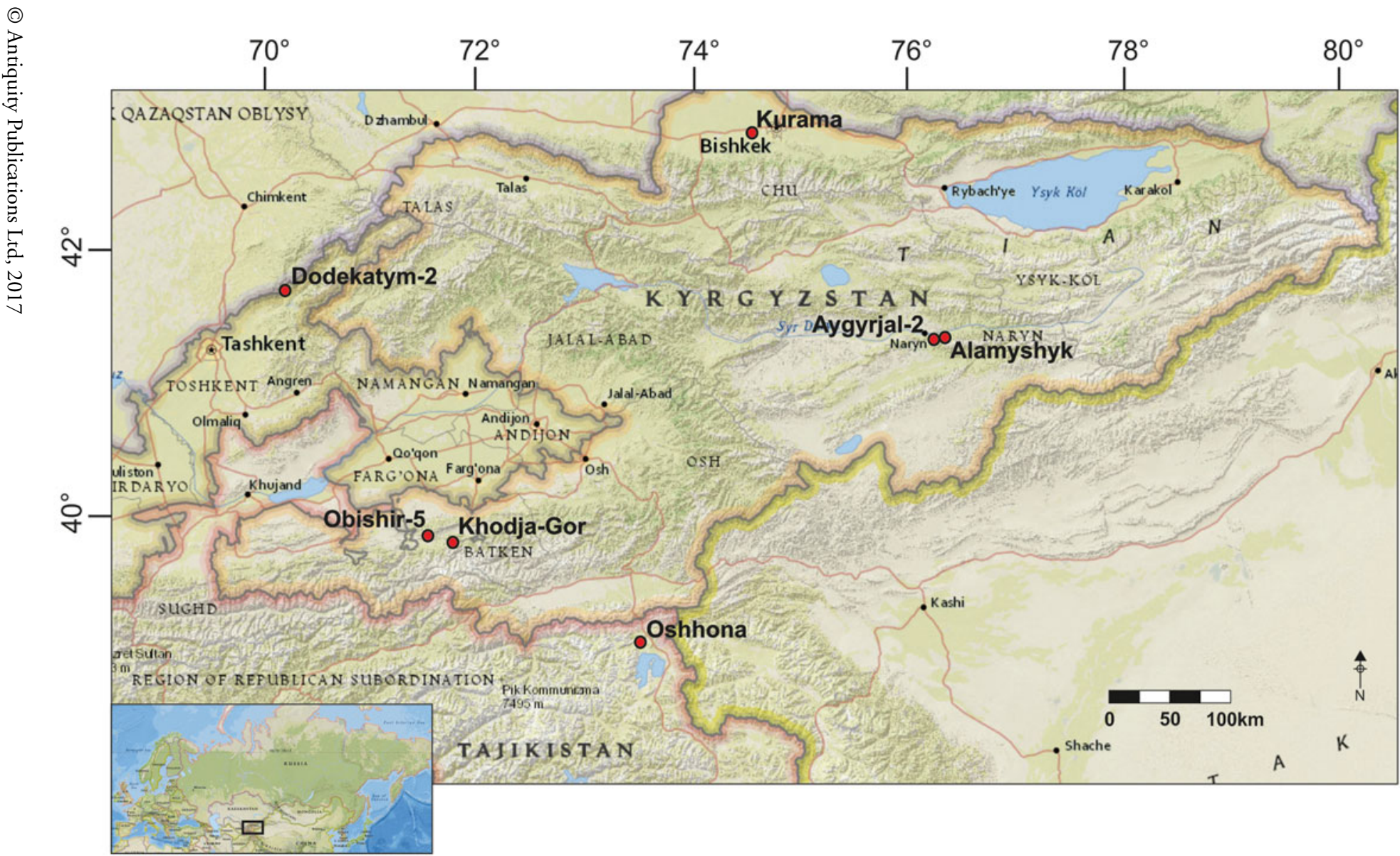

Figure 1. The location of archaeological sites mentioned in the article. Map produced using National Geographic Basemap and ArcGIS Online. 


\section{New investigations of the Epipalaeolithic in western Central Asia}

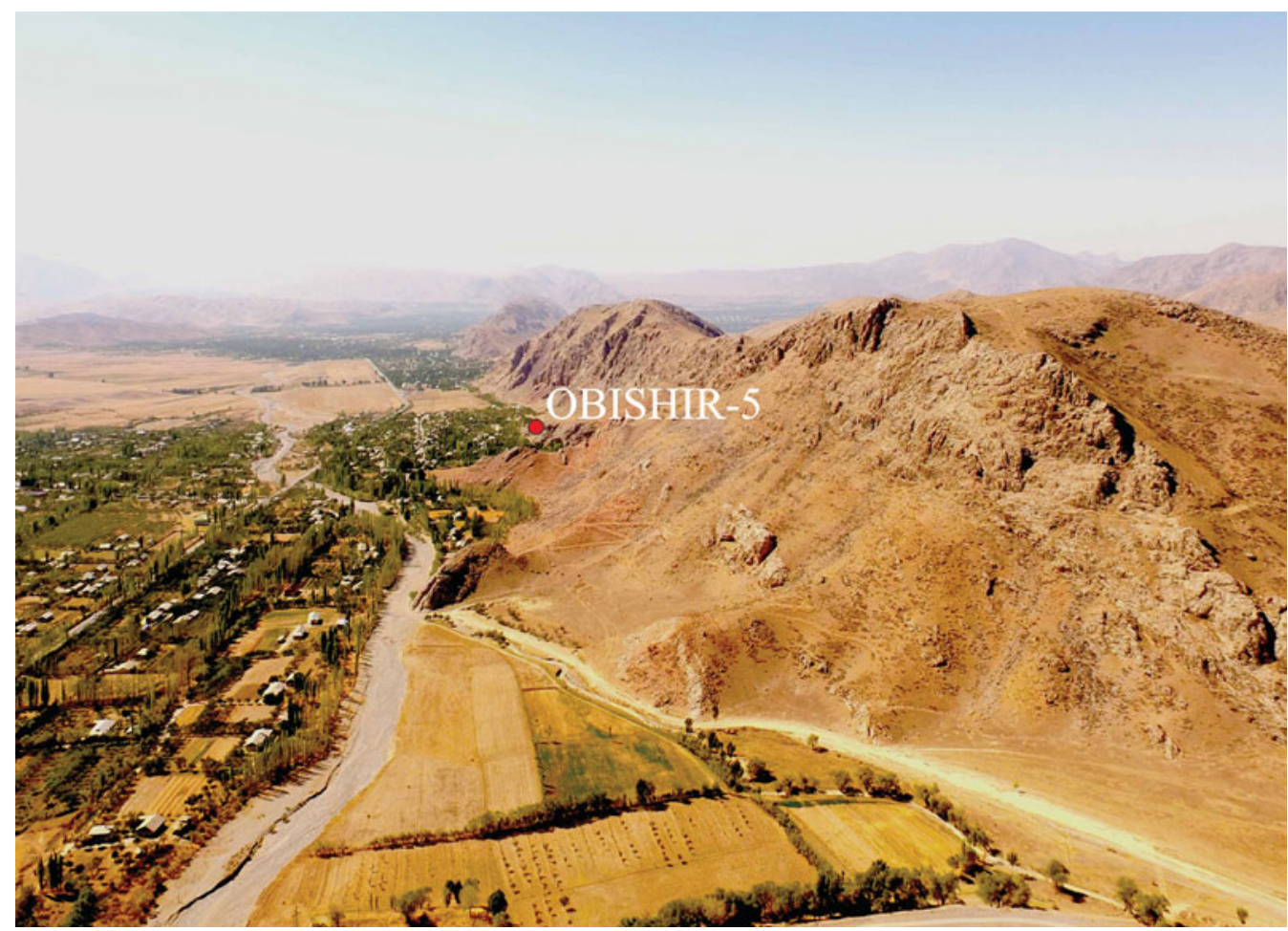

Figure 2. Obishir-5, as seen from the east.
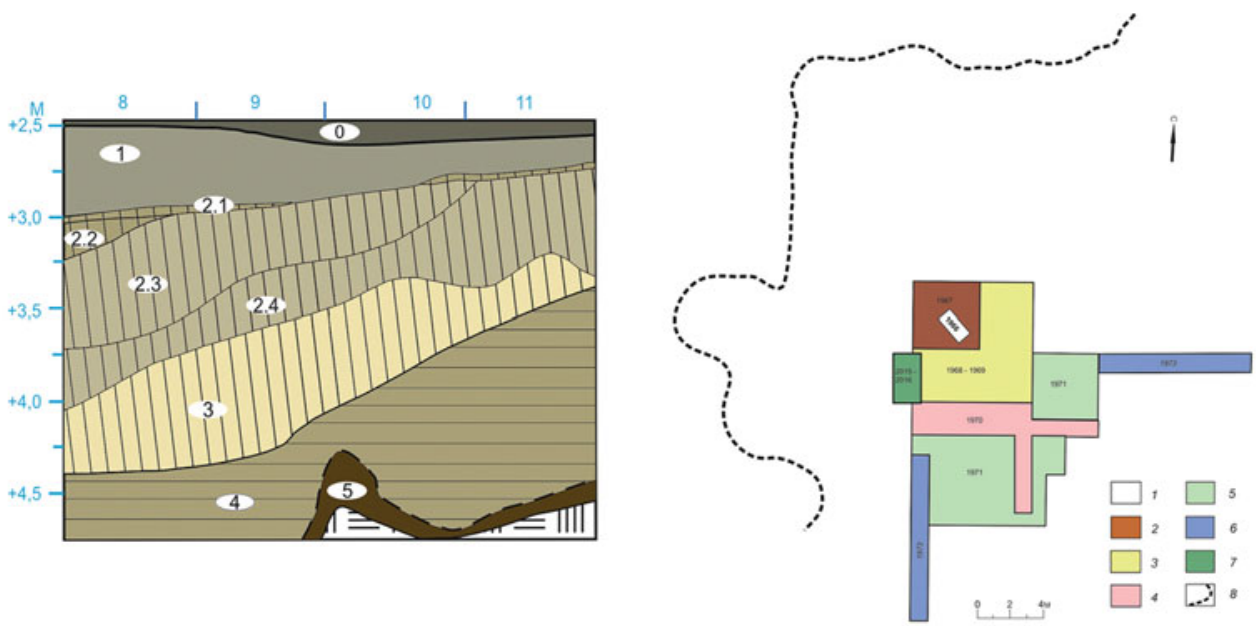

Figure 3. Stratigraphy and excavation plan of Obishir-5 (after the 2016 excavation). The numbering of layers does not follow the original numeration by Islamov (1980). 
Table 1. Radiocarbon dates from Obishir-5; given date ranges correspond to 1-sigma (68.2 per cent) probability range, calibrated using IntCal13 (OXCAL version 4.3).

\begin{tabular}{lcccc}
\hline Layer & Laboratory no. Conventional radiocarbon age & Calibrated & Dating materials \\
\hline & & & & \\
1 (middle part) & PLD-31751 & $1650 \pm 20 \mathrm{BP}$ & $1570-1530 \mathrm{CalBP}$ & charcoal \\
2 (middle part) & PLD-31752 & $7405 \pm 25 \mathrm{BP}$ & $8317-8179 \mathrm{CalBP}$ & charcoal \\
2 (lower part) & PLD-31753 & $9410 \pm 30 \mathrm{BP}$ & $10717-10571 \mathrm{CalBP}$ charcoal \\
\hline
\end{tabular}

during the Last Glacial Maximum. Layers 2-5 contained Epipalaeolithic material. Three AMS ${ }^{14} \mathrm{C}$ dates (Paleo Laboratory Ltd, Japan) are currently available for layers 1 and 2 (Table 1).

The assemblage recovered from layers 2-5 includes more than 2200 lithic artefacts (Figure 4). Technical and typological analysis allowed us to define two distinct technocomplexes: one from layers 2-3, and the second from layers 4-5. The industry from layers 2-3 is characterised by the pressure knapping of bladelets from volumetric and narrowfaced cores. The toolkit consists of microblades with ventral retouch, perforators and notched tools, thumbnail endscrapers, micro splinted pieces and burins. A pendant and a pendant blank manufactured from local talcite and serpentinite were recovered from layer 2 (Figure 5). The closest source of these raw materials is situated approximately $4.5 \mathrm{~km}$ from the site. Layer 2 also yielded human remains associated with the Epipalaeolithic of the region. The specimen is a right upper first deciduous incisor, quite worn and with a mostly resorbed root (Figure 6). We estimate the age of the individual at roughly six years, based on recent dental standards (Ubelaker 1978).

The lithic assemblage from layers $4-5$ is characterised by volumetric and narrow-faced cores for bladelets, which were created by soft hammer percussion. The toolkit includes bladelets with dorsal retouch, backed bladelets and end-scrapers.

Comparative analysis suggests that the assemblages from layers 2-3 are similar to the Epipalaeolithic complexes from the central Tian-Shan area (Alamyshyk, Aygyrjal-2) and the Pamir region (Oshhona), which date to between 13000-7000 cal BP (Motuzaite Matuzeviciute et al. 2017). The material from layers 4-5 has analogies with the Upper Palaeolithic sites of the Tian-Shan (Kurama, layers 1-2, Dodekatym-2, layers 2-4) and Pamiro-Alai regions (Khodja-Gor), with dates between 28 000-23000 cal BP (Kolobova et al. 2011).

These conclusions, however, must be regarded with caution, as the sediments of Obishir5 bear traces of colluvial re-deposition, and the mixing of artefacts between layers cannot currently be excluded.

Materials from layers 2-3 enabled the identification of a new variant of Epipalaeolithic culture in the region, characterised by unique retouched bladelets and pressure knapping methods used during stone tool production. Using analogies with other sites, we believe that this unit may be widely spread, from the Pamir Mountains to the south and the Tian Shan to the north and east.

Until recently, a chronological and cultural gap between Late Pleistocene and Early Holocene peopling of western Central Asia has been hypothesised. The Upper Palaeolithic assemblages of Dodekatym-2 (Uzbekistan) and Kurama (Kyrgyzstan) (both dated to 23000

(C) Antiquity Publications Ltd, 2017 

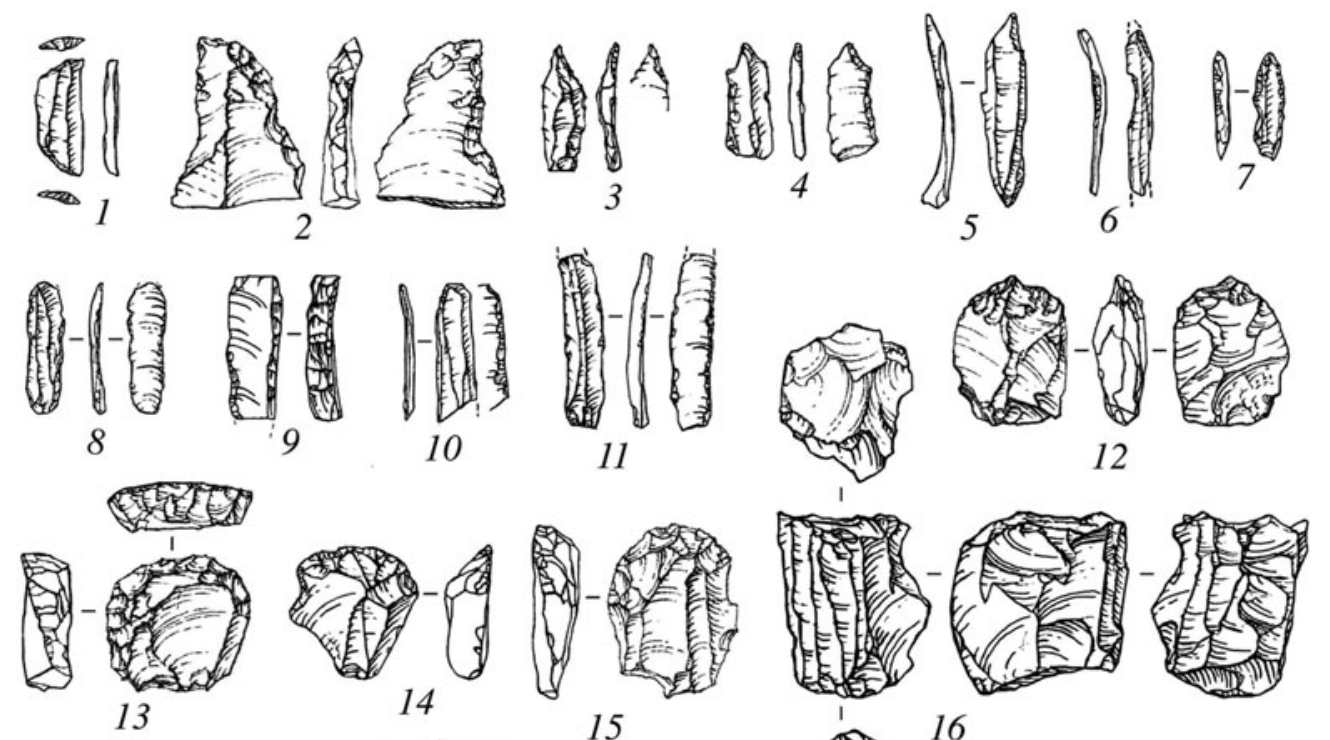

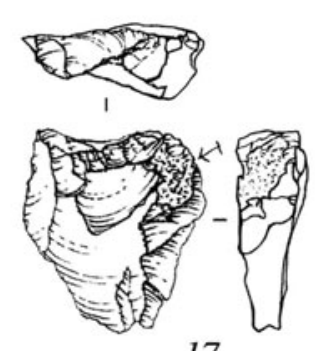

17
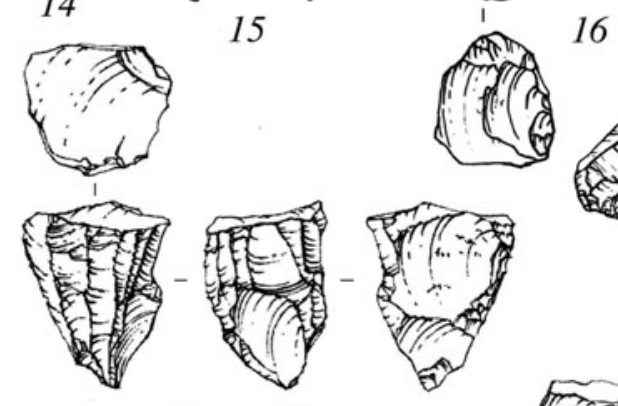

18
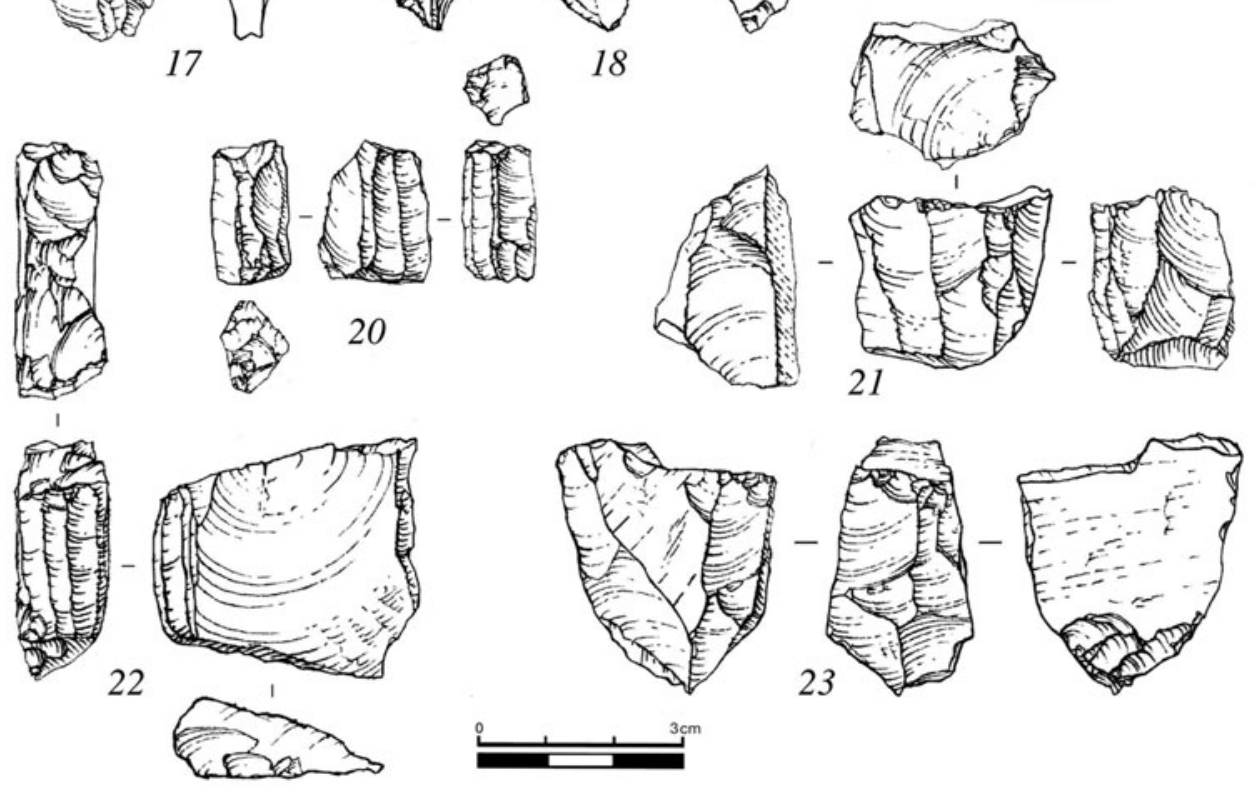

Figure 4. Lithic artefacts from Obishir-5. 

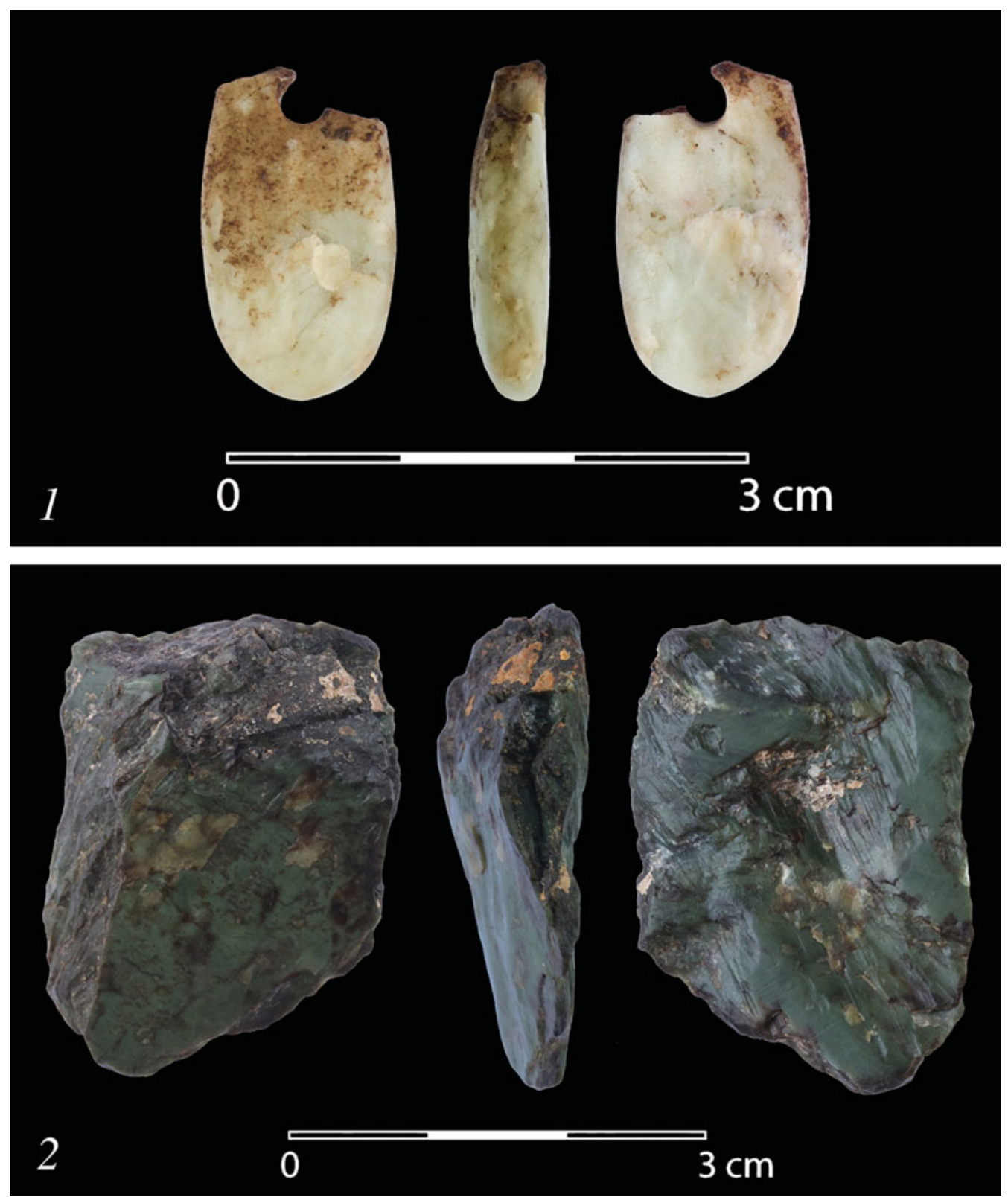

Figure 5. Stone ornaments from Obishir-5.

cal BP) are characterised by scalene triangles, Arzheneh points and backed bladelets, accompanied by carinated and single-platform cores. Several thousand years later in Central Asia, Mesolithic and Epipalaeolithic techno-complexes (20000 BP) with different types of geometric and non-geometric microliths appeared. The reassessment of Obishir-5, with its Final Pleistocene and Early Holocene assemblages, could illuminate questions of relationships between Upper Palaeolithic and Epipalaeolithic inhabitants. Our preliminary (C) Antiquity Publications Ltd, 2017 
data is evidence for the cultural replacement of the industries, without any sign of transition. This area was occupied in the Upper Palaeolithic and Epipalaeolithic by various groups that produced differing lithic techno-

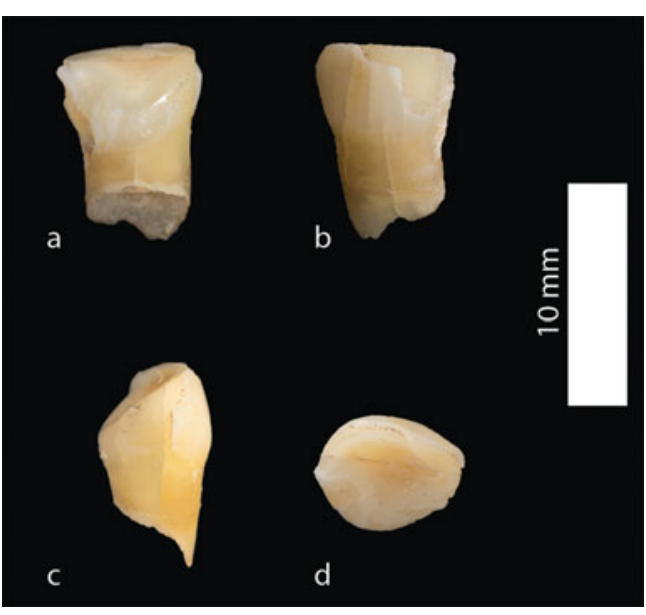

Figure 6. The upper deciduous incisor from Obishir-5. complexes. Considering the scarcity of Upper Palaeolithic and Epipalaeolithic sites in western Central Asia, Obishir-5 represents the only source of information concerning the Final Pleistocene to Early Holocene transition in the region.

\section{Acknowledgements}

The analytical aspect of this research was supported by the Russian Science Foundation (project 14-5000036). Support for field studies was provided by grants from the President of the Russian Federation (MD-2845.2017.6), the Russian Humanitarian Science Foundation (15-31-01000) and the Project of Altai State University (33.867.2017.ПЧ). Dating was performed courtesy of Katsuhiko Ohnuma, Kokusihikan University, Tokyo ('Formation of Nomadic Societies in Ancient Eurasia' Project).

\section{References}

Islamov, U.I. 1980. Obishir culture. Tashkent: Phan. Kolobova, K.A., A.I. Krivoshapkin, A.P. Derevianko \& U.I. Islamov. 2011. The Upper Paleolithic site of Dodekatym-2 in Uzbekistan. Archaeology, Ethnology \& Anthropology of Eurasia 39: 2-21. https://doi.org/10.1016/j.aeae.2012.02.002

Motuzaite Matuzeviciute, G., R.C. Preece, S. Wang, L. Colominas, K. Ohnuma, S. Kume, A. Abdykanova \& M.K. Jones. 2017. Ecology and subsistence at the Mesolithic and Bronze Age site of Aigyrzhal-2, Naryn Valley, Kyrgyzstan. Quaternary International 437 B: 35-49. https://doi.org/10.1016/j.quaint.2015.06.065

UBELAKer, D.H. 1978. Human skeletal remains. Washington, D.C.: Taraxacum. 